ORIGINAL ARTICLE

\title{
The incidence and mortality for meningococcal disease associated with area deprivation: an ecological study of hospital episode statistics
}

\author{
R S Heyderman, Y Ben-Shlomo, C A Brennan, M Somerset
}

Arch Dis Child 2004;89:1064-1068. doi: 10.1136/adc.2003.036004

See end of article for authors' affiliations

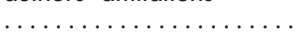

Correspondence to: Dr R S Heyderman, Department of Pathology \& Microbiology, School of Medical Sciences, University of Bristol University Walk, Bristol BS8 1TD, UK;

r.heyderman@bristol.ac.uk

Accepted

16 February 2004

\begin{abstract}
Aims: To determine whether incidence, mortality, and case fatality for meningococcal disease (MD) differs by area deprivation, and if this has changed over time.

Methods: The population of children aged less than 5 years with MD was analysed as quintiles of area deprivation scores over two time periods, 1995-99 and 1991-94. Annual age standardised rates were calculated and the association between incidence, mortality, and area deprivation quintiles assessed using Poisson regression and the risk ratios determined. Case fatality was calculated from the odds ratio of mortality by area deprivation score for the two time periods.

Results: There were 10524 cases of MD and 441 deaths (4.2\%). Incidence rates were higher for 1995-99 (45.4 per 100 000) compared to $1991-94$ (27.4 per 100 000). Mortality rates remained stable over time, indicating a decline in risk of death of around $40 \%$. The incidence rates for the most deprived quintile were around twice those for the most affluent quintile, but this gradient declined over time. A threefold gradient was seen for mortality rates across the top and bottom quintiles, which was constant over time. The odds of mortality did not show a linear pattern, with mortality being lowest in the first and highest in the second and fifth area deprivation quintiles.

Conclusions: These data show that MD incidence and mortality are socially patterned. The determinants of case fatality are more complex and require further investigation.
\end{abstract}

I: the United Kingdom, Neisseria meningitidis is the commonest cause of bacterial meningitis in children and young adults, and is a frequent cause of septicaemia and shock in this age group. ${ }^{12}$ Notifications of both clinical and laboratory confirmed cases of meningococcal disease reached a 10 year high in $1999 .{ }^{2}$ Although the meningococcal serogroup $C$ vaccine has had a dramatic impact on serogroup $\mathrm{C}$ disease, ${ }^{3}$ the protective effect of the vaccine is serogroup specific. ${ }^{4}$ Therefore, meningitis and septicaemia caused by the more prevalent serogroup B meningococcus (approximately $65 \%$ of cases) has been unaffected.

Numerous genetic, immunological, and environmental factors have been implicated in the aetiology of meningococcal meningitis and septicaemia. ${ }^{5-14}$ A positive association has been observed between social deprivation and the risk of meningococcal disease in both case-control studies ${ }^{812}{ }^{15}$ and prospectively collected data using an ecological marker of social deprivation. ${ }^{16-18}$ These studies suggest that poorer areas or households are at greater risk of developing meningococcal disease, but two key questions remain. Firstly, as the incidence of meningococcal disease has increased in the UK, ${ }^{2}$ has this pattern of increased risk also altered over time? Secondly, as poorer children have a greater risk of death from more common infectious conditions such as pneumonia, ${ }^{19}{ }^{20}$ does social deprivation also influence meningococcal mortality?

No previous study of meningococcal infection has been adequately powered to examine whether social deprivation influences mortality rather than the incidence of this disease per se. In this study, we have made use of data on meningococcal disease in children under 5 years of age for the whole of England available through the national hospital episode statistics (HES) database. Our specific objectives were to determine whether children living in poorer areas have higher incidence and mortality rates for meningococcal disease and whether the strength of these associations has changed between 1991 and 1999.

\section{METHODS \\ Subjects}

All cases aged less than 5 years of age with a diagnosis of meningococcal disease (ICD codes: 036 ICD-9, A39, ICD-10) and living in an English electoral ward were identified for the period 1991-99 (National HES data). Access to data from the HES database was obtained through the Department of Health after review by the security and confidentiality advisory group (an independent committee). For each subject, the following additional data were available: sex, electoral ward code, year of admission, source of admission, a discharge code (which includes death as an outcome), age in exact years, an NHS healthcare trust code, postcode, and date of birth. The last two variables were both encrypted to maintain anonymity but to enable record linkage. Repeat hospital episodes for the same child were identified by creating a "pseudo-unique" identifier based on children with the same diagnosis, sex, postcode, and date of birth. In this way multiple episodes were identified, and only the first was retained for analysis to avoid overcounting events. The numerator for each electoral ward was then calculated by summating all individuals with a diagnosis of meningococcal disease for that ward. The equivalent denominator data were taken from the 1991 census for boys and girls by age group for the same wards. Because of the introduction of ICD-10 coding in 1995, which contains a simplified but modified set of diagnostic criteria, we decided to split the time period into two categories, 1991-94 and 1995-99, so that within each period there would be no artifactual differences due to the change in coding. 


\section{Assessment of area deprivation}

Routine denominator data for the number of boys and girls under 5 years by electoral ward were obtained from Manchester Information and Associated Services (MIMAS) from the 1991 census. Area deprivation was measured using the 1991 Townsend index for each electoral ward. ${ }^{21}$ This is a standardised score (mean 0 ) based on the distribution of four variables: unemployment, car ownership, overcrowding, and housing tenure. A positive score indicates greater area deprivation, while a negative score indicates greater affluence. This score was used to allocate electoral wards to quintiles (five equal sized groups) so that quintile 5 consists of wards in the worst $20 \%$ area deprivation. This categorisation was done a priori on the basis of the large number of incident cases and to better characterise any non-linear trends.

\section{Statistical analysis}

Analyses were done separately for boys and girls and repeated for both incidence and mortality. Annual age standardised rates were calculated using the direct method with the distribution of boys and girls under 5 as the standard population. The association between incidence, mortality, and area deprivation quintiles was calculated using Poisson regression. Risk ratios and 95\% confidence intervals were calculated for each quintile relative to the middle quintile (quintile 3 ) as the rates for quintile 1 were less robust due to small numbers of events, particularly for mortality. These analyses were also repeated using the negative binomial model to check for over dispersion, but there was no evidence that this was the case. We repeated our Poisson models using deprivation score as an ordinal variable to compare differences in the risk ratio for area deprivation score and outcome for the two time periods. The beta coefficient for area deprivation assumes the true association is linear. The differences between the beta coefficients for each time period and for both incidence and mortality were then calculated, and the $95 \%$ confidence interval for the difference calculated using the pooled standard errors. These were then exponentiated to produce the ratio of risk ratios with its respective $95 \% \mathrm{CI}$ and two sided $\mathrm{p}$ value from normal distribution tables. This was done to investigate whether there was an interaction between the effects of area deprivation and time period-that is, was the effect of poverty on mortality, for example, worse in the second period compared to the first?

We finally used a logistic regression model to calculate the odds ratio of mortality by area deprivation score, adjusting for age and sex to determine if case fatality systematically differed for poorer areas. We chose to use this approach rather than model case fatality using Poisson regression as we felt that this would be more statistically efficient given the imprecision of the mortality rates for some strata.

\section{RESULTS}

Over the nine year period, there were 10524 cases of meningococcal disease ( 5892 boys, 4632 girls), from which there were 441 deaths (4.2\%) (238 boys, 203 girls). On average, the number of events per quintile was 526 for incidence and 22 for mortality across both time periods.

\section{Changing incidence of meningococcal disease}

The overall annual incidence rate was 41.0 and 33.7 per 100000 for boys and girls respectively. Incidence rates were higher for the second time period (45.4 per 100000 for 199599) compared to the first (27.4 per 100000 for 1991-94). For each time period there was a marked linear increase in incidence rate by quintiles of deprivation for both boys and girls (see table 1) so that rates for the most deprived $20 \%$ were around twice those for the most affluent $20 \%$. However, the gradient between area deprivation and incidence declined over the two time periods despite the increase in overall rates. We formally compared these changes by calculating the ratio of risk for a one unit increase in deprivation for these two time periods. This was 0.95 (95\% CI 0.91 to $0.99, \mathrm{p}=0.02$ ) for boys and 0.92 (95\% CI 0.87 to $0.96, \mathrm{p}=0.0005)$ for girls, indicating a less steep gradient for the second time period for both.

\section{Trends in mortality for meningococcal disease}

Overall the mortality rates remained remarkably stable over the two time periods: 1.59 per 100000 for $1991-94$ and 1.57 per 100000 for 1995-99. In parallel with the observed linear increase in incidence rate by quintiles of deprivation, an even stronger threefold gradient was seen for mortality rates across the top and bottom quintiles. The patterns were similar for each time period, and for both boys and girls, though the rates were lower and less stable, based on a far fewer number of events. However, this risk associated for mortality by area deprivation did not alter over time. The ratio of risk for the two time periods in relation to mortality was 1.01 (95\% CI 0.82 to $1.25, \mathrm{p}=0.90)$ for boys and 0.94 (95\% CI 0.74 to $1.18, \mathrm{p}=0.58$ ) for girls.

\section{Odds of mortality given risk of incidence}

Overall, the case fatality declined by around $40 \%$ as mortality rates remained fairly stable while there was a marked increase in incidence rates for meningococcal disease. Therefore to determine whether the higher observed mortality rates for poorer areas indicated variations in case fatality or merely reflected the higher incidence rates, we calculated the odds ratio of mortality by area deprivation score for the two time periods (table 2). This analysis indicated an increased risk of mortality by worse area deprivation score, but the pattern was non-linear. In general the lowest odds were seen in the most affluent quintile and highest odds seen in the second and fifth quintiles. To test whether this $\mathrm{N}$ shaped pattern may have been due to chance we compared the fit of our models using deprivation as a dummy nonlinear term and as an ordinal term, which assumes linearity, using the likelihood ratio test. All the $\mathrm{p}$ values for these comparisons were greater than 0.05 , suggesting that a linear pattern was as consistent with the data as an $\mathrm{N}$-shaped pattern.

We also repeated some of our analyses using quartiles of area deprivation as we were concerned that the $\mathrm{N}$-shaped pattern may have been an artefact of this arbitrary categorisation. The revised odds ratios for quintiles of area deprivation for boys and girls combined are as follows: 199194: $\mathrm{Q} 1=1.0, \quad \mathrm{Q} 2=1.12, \quad \mathrm{Q} 3=1.48, \quad \mathrm{Q}=1.16 ; \quad 1995-99$ : $\mathrm{Q} 1=1.0, \mathrm{Q} 2=1.85, \mathrm{Q} 3=1.10, \mathrm{Q} 4=1.75$. For the earlier time period the pattern has changed to look more like an inverted $\mathrm{U}$, but for the second time period it continues to show an $\mathrm{N}$-shape.

The trend per unit increase in area deprivation was slightly stronger for the second time period, but this is compatible with chance variation.

\section{DISCUSSION}

Using national hospital episode statistics for children aged less than 5 years, we confirm the marked increase in the incidence of meningococcal disease in the UK reported through other laboratory and clinical based notification systems. ${ }^{2}$ This rise in incidence may be attributable in part to enhanced surveillance ${ }^{22} 23$ and improvements in molecular diagnosis, ${ }^{24}$ but there is considerable evidence to suggest that subsequent to these changes in data collection the upward trend has continued. ${ }^{2}$ At the time of writing, data for 


\begin{tabular}{|c|c|c|c|c|c|c|c|c|c|c|}
\hline & \multicolumn{10}{|c|}{ Townsend deprivation score (quintiles) } \\
\hline & \multicolumn{5}{|l|}{$1991-94$} & \multicolumn{5}{|l|}{$1995-99$} \\
\hline & Most affluent & 2nd & 3 rd & 4th & Most deprived & Most affluent & 2nd & 3rd & $4 \mathrm{th}$ & $\begin{array}{l}\text { Most } \\
\text { deprived }\end{array}$ \\
\hline $\begin{array}{l}\text { Boys } \\
\text { Incidence rate per }\end{array}$ & 15.4 & 19.4 & 26.2 & 31.0 & 39.2 & 33.5 & 35.5 & 41.0 & 52.3 & 63.0 \\
\hline $\begin{array}{l}\text { Risk ratio } \\
(95 \% \mathrm{CI})\end{array}$ & $\begin{array}{l}0.59 \\
0.47 \text { to } 0.73\end{array}$ & $\begin{array}{l}0.74 \\
0.61 \text { to } 0.90\end{array}$ & 1.0 & $\begin{array}{l}1.19 \\
1.02 \text { to } 1.38\end{array}$ & $\begin{array}{l}1.50 \\
1.31 \text { to } 1.72\end{array}$ & $\begin{array}{l}0.82 \\
0.71 \text { to } 0.94\end{array}$ & $\begin{array}{l}0.86 \\
40.76 \text { to } 0.99\end{array}$ & 1.0 & $\begin{array}{l}1.27 \\
1.15 \text { to } 1.42\end{array}$ & $\begin{array}{l}1.54 \\
2.39 \text { to } 1.69\end{array}$ \\
\hline $\begin{array}{l}\text { Mortality rate per } \\
100000\end{array}$ & 0.7 & 1.1 & 1.3 & 2.1 & 2.0 & 0.6 & 1.4 & 1.1 & 1.9 & 2.2 \\
\hline $\begin{array}{l}\text { Risk ratio } \\
\qquad(95 \% \mathrm{Cl})\end{array}$ & $\begin{array}{l}0.53 \\
0.19 \text { to } 1.49\end{array}$ & $\begin{array}{l}0.85 \\
0.36 \text { to } 2.00\end{array}$ & 1.0 & $\begin{array}{l}1.69 \\
0.89 \text { to } 3.22\end{array}$ & $\begin{array}{l}1.56 \\
0.84 \text { to } 2.89\end{array}$ & $\begin{array}{l}0.59 \\
0.23 \text { to } 1.54\end{array}$ & $\begin{array}{l}1.32 \\
0.64 \text { to } 2.73\end{array}$ & $3^{1.0}$ & $\begin{array}{l}1.77 \\
0.95 \text { to } 3.27\end{array}$ & $\begin{array}{l}2.03 \\
1.14 \text { to } 3.63\end{array}$ \\
\hline $\begin{array}{l}\text { Girls } \\
\text { Incidence rate per } \\
100000\end{array}$ & 11.6 & 16.2 & 19.5 & 27.6 & 33.0 & 27.4 & 30.0 & 36.2 & 40.9 & 51.0 \\
\hline $\begin{array}{l}\text { Risk ratio } \\
\qquad(95 \% \mathrm{Cl})\end{array}$ & $\begin{array}{l}0.60 \\
0.46 \text { to } 0.77\end{array}$ & $\begin{array}{l}0.84 \\
0.67 \text { to } 1.04\end{array}$ & 1.0 & $\begin{array}{l}1.42 \\
1.19 \text { to } 1.69\end{array}$ & $\begin{array}{l}1.70 \\
1.45 \text { to } 1.99\end{array}$ & $\begin{array}{l}0.76 \\
0.65 \text { to } 0.89\end{array}$ & $\begin{array}{l}0.83 \\
0.72 \text { to } 0.96\end{array}$ & $5^{1.0}$ & $\begin{array}{l}1.13 \\
1.00 \text { to } 1.27\end{array}$ & $\begin{array}{l}1.41 \\
1.27 \text { to } 1.57\end{array}$ \\
\hline $\begin{array}{l}\text { Mortality rate per } \\
100000\end{array}$ & 0.1 & 1.5 & 1.0 & 1.8 & 2.1 & 0.7 & 1.4 & 0.9 & 1.2 & 2.1 \\
\hline $\begin{array}{l}\text { Risk ratio } \\
(95 \% \mathrm{Cl})\end{array}$ & $\begin{array}{l}0.14 \\
0.02 \text { to } 1.09\end{array}$ & $\begin{array}{l}1.49 \\
0.64 \text { to } 3.45\end{array}$ & 1.0 & $\begin{array}{l}1.77 \\
0.85 \text { to } 3.67\end{array}$ & $\begin{array}{l}2.02 \\
1.02 \text { to } 4.00\end{array}$ & $\begin{array}{l}0.76 \\
0.28 \text { to } 2.06\end{array}$ & $\begin{array}{l}1.58 \\
0.72 \text { to } 3.47\end{array}$ & $7^{1.0}$ & $\begin{array}{l}1.36 \\
0.66 \text { to } 2.81\end{array}$ & $\begin{array}{l}2.29 \\
1.20 \text { to } 4.36\end{array}$ \\
\hline
\end{tabular}

2000/2001 were not available to assess the impact of meningococcal serogroup $C$ vaccination in the UK. ${ }^{3}$

We have used this large data set to also show that there has been an appreciable fall in the risk of death (40\%) from meningococcal disease among young children. This supports two recently reported small hospital inpatient studies which suggest a fall in mortality for meningococcal disease, particularly among septicaemic cases (in excess of 20\% falling to less than 10\%). ${ }^{25}$ Although increased reporting of mild cases may account for some of this trend,, ${ }^{22}{ }^{23}$ increased awareness, targeted postgraduate training, and the concentration of management of a critically ill children at specialist centres are thought to have had a significant impact. $^{25} 26$

These data confirm the previously reported association between the incidence of meningococcal disease and social deprivation in childhood, ${ }^{8}{ }^{12}{ }^{15-18}$ and show for the first time an association between social deprivation and meningococcal mortality. We show that alongside an increase in the burden of meningococcal disease over the last nine years, the incidence and the mortality rates have remained highest among children from the most deprived electoral wards. Given the higher incidence rates in poorer areas, it is not unexpected that these areas also experience the highest mortality as well. Surprisingly, the odds of mortality, an indirect measure of case fatality, showed an $\mathrm{N}$-shaped pattern. In general, case fatality was lowest in the first and was highest in the second most affluent and poorest quintiles. This was more marked for the second time period. This pattern may have been a chance finding and our results were equally consistent with a simpler linear trend. Further data will enable us to get more precise estimates, and this pattern will either attenuate, suggesting random variation, or persist, in which case further research is required to elucidate possible explanations.

The association between area deprivation and meningococcal disease is potentially of significant public health importance as it provides an avenue for population based primary prevention and intervention. The relation between childhood poverty and the incidence and mortality from

Table 2 Odds ratio for mortality as an indicator of case fatality from meningococcal disease among children with disease by Townsend deprivation quintiles

\begin{tabular}{|c|c|c|c|c|c|c|c|c|c|}
\hline \multirow[b]{2}{*}{ Deprivation quintiles } & \multicolumn{3}{|l|}{ Boys } & \multicolumn{3}{|l|}{ Girls } & \multicolumn{3}{|l|}{ All } \\
\hline & Odds ratio* & $95 \% \mathrm{Cl}$ & $p$ value & Odds ratio & $95 \% \mathrm{Cl}$ & p value & Odds ratio & $95 \% \mathrm{Cl}$ & $p$ value \\
\hline \multicolumn{10}{|l|}{$1991-94$} \\
\hline 1 (most affluent) & 0.86 & 0.30 to 2.49 & 0.79 & 0.23 & 0.03 to 1.85 & 0.17 & 0.60 & 0.24 to 1.50 & 0.28 \\
\hline 2 & 1.19 & 0.49 to 2.84 & 0.70 & 1.89 & 0.79 to 4.52 & 0.15 & 1.49 & 0.81 to 2.76 & 0.20 \\
\hline 3 & 1.00 & & & 1.00 & & & 1.00 & & \\
\hline 4 & 1.45 & 0.75 to 2.82 & 0.27 & 1.27 & 0.60 to 2.69 & 0.54 & 1.36 & 0.83 to 2.23 & 0.23 \\
\hline 5 (most deprived) & 1.03 & 0.55 to 1.94 & 0.93 & 1.20 & 0.59 to 2.43 & 0.61 & 1.12 & 0.70 to 1.79 & 0.64 \\
\hline Odds per quintile & 1.01 & 0.86 to 1.18 & 0.94 & 1.05 & 0.87 to 1.25 & 0.63 & 1.03 & 0.91 to 1.16 & 0.66 \\
\hline \multicolumn{10}{|l|}{ 1995-99 } \\
\hline 1 (most affluent) & 0.71 & 0.27 to 1.86 & 0.48 & 1.02 & 0.37 to 2.79 & 0.98 & 0.83 & 0.42 to 1.67 & 0.61 \\
\hline 2 & 1.58 & 0.75 to 3.33 & 0.22 & 1.93 & 0.86 to 4.32 & 0.11 & 1.72 & 1.00 to 2.96 & 0.05 \\
\hline 3 & 1.00 & & & 1.00 & & & 1.00 & & \\
\hline 4 & 1.44 & 0.77 to 2.70 & 0.25 & 1.21 & 0.58 to 2.53 & 0.60 & 1.33 & 0.83 to 2.14 & 0.24 \\
\hline 5 (most deprived) & 1.36 & 0.75 to 2.44 & 0.31 & 1.65 & 0.86 to 3.18 & 0.13 & 1.47 & 0.95 to 2.28 & 0.08 \\
\hline Odds per quintile & 1.08 & 0.94 to 1.24 & 0.28 & 1.07 & 0.92 to 1.25 & 0.37 & 1.08 & 0.97 to 1.19 & 0.17 \\
\hline
\end{tabular}


infectious diseases such as respiratory tract infections, diarrhoeal diseases, and measles is well established, particularly in resource-poor countries. ${ }^{20}$ However, in the absence of severe malnutrition in the UK, the precise mechanisms through which socioeconomic conditions operate are complex. In relation to the incidence of meningococcal disease, social deprivation may be a proxy marker for many other cofactors such as overcrowding, damp living conditions, passive smoking, viral upper respiratory tract infections, and other socially patterned exposures. ${ }^{8-12}{ }^{27}$ These factors may lead to increased exposure and/or carriage of Neisseria meningitidis or impaired host defences against bacterial invasion. ${ }^{7}$ It is unlikely that any genetic risk factors for either meningococcal disease susceptibility or severity would show such strong social patterning to explain our observations. Once admitted to hospital there is no evidence that management or treatment is determined by social deprivation. Why our indirect measure of case fatality showed an N-shaped pattern is uncertain. Possible explanations include chance variation, delays in seeking healthcare, or differences in the likelihood of receiving early treatment prior to diagnosis at a primary care level. ${ }^{19} 28-32$

\section{Strengths and limitations of the study}

The use of a large national dataset has provided us with greater statistical power to analyse both incidence and mortality. The results are likely to be generalisable throughout the UK and potentially to other similar healthcare systems. However the study is limited by a number of factors. Despite aggregating data from nine years, we still had relatively small numbers of deaths once we had stratified by sex, time period, and area deprivation. Although clinical and laboratory diagnosis of childhood meningococcal disease, particularly in its severe forms, is generally reliable, the validity of our findings relies on accurate diagnostic coding. It is possible that there was some diagnostic misclassification of meningococcal disease under other conditions during the recording of the HES data, and deaths occurring before admission to hospital would not have been recorded. Ramsay et al have shown that reporting practice has changed between 1989 and 1995 and that the ascertainment of clinically diagnosed disease has improved. ${ }^{22}$ While this may partially explain the increase in absolute incidence rates, as well as changes in ICD coding, there is no reason to believe that this would be systematically affected by electoral ward and hence area deprivation score.

We have used an ecological rather than individual marker of deprivation. Our results may therefore reflect the "ecological fallacy" as associations at an area level may not be reflected at an individual level. ${ }^{33}$ However, this is unlikely as the same pattern has been observed in individual based studies and research for other infectious diseases.8 ${ }^{812} 1520$

We have attempted to remove duplicate admissions. For mortality this is not a problem as the event can only occur once. For incidence this is more problematic as subjects may be transferred both within an NHS healthcare trust, generating more than one finished consultant episode, or between trusts because of the need for specialist intensive care. Our method was able to identify such repeat admissions and only use the first episode; however, because the data were based on a pseudo unique identifier it is possible that errors will have occurred, though again it is unlikely that this was systematically biased by area deprivation.

Improving case management has been shown to improve the outcome of childhood pneumonia. ${ }^{34}$ Early recognition and prompt antibiotic treatment are key components in the avoidance of the severe consequences of meningococcal of meningitis and septicaemia. Variations in symptom recognition and access to primary care or emergency departments are likely to vary in different health, material, and cultural settings. ${ }^{35}$ Our findings suggest that although the main determinant of differences in disease mortality by area deprivation is risk of disease incidence, there may be an additional component due to sociocultural differences in disease presentation and/or early management. Although minimisation of poverty will have the greatest impact on disease prevention, in the short to medium term, improvements in access to healthcare and earlier treatment are more likely to reduce the rate of mortality from meningococcal disease for all social groups. Further studies to understand the mechanisms of the association between death from meningococcal disease and social deprivation will help determine the implications for clinicians and policymakers.

\section{ACKNOWLEDGEMENTS}

This work was supported by the MRC Health Services Research Collaboration and the Meningitis Trust. MS is currently in receipt of an NHS National Primary Care Researcher Development Award. The Department of Social Medicine of the University of Bristol is the lead centre of the MRC Health Services Research Collaboration. We are grateful to Davidson Ho for assistance with data management and thank Jonathon Sterne for statistical advice.

\section{Authors' affiliations}

R S Heyderman, C A Brennan, Department of Pathology \&

Microbiology, University of Bristol, UK

Y Ben-Shlomo, Department of Social Medicine, University of Bristol, UK M Somerset, Division of Primary Health Care, University of Bristol, UK

\section{REFERENCES}

1 Heyderman RS, Klein NJ. Emergency management of meningitis. J R Soc Med 2000:93:225-9.

2 http://www.hpa.org.uk/infections/topics_az/meningo/menu.htm.

3 Balmer $\mathrm{P}$, Borrow R, Miller $\mathrm{E}$. Impact of meningococcal $\mathrm{C}$ conjugate vaccine in the UK. J Med Microbiol 2002;51:717-22.

4 Pollard AJ, Moxon ER. The meningococcus tamed? Arch Dis Child 2002;87:13-17.

5 Blackwell CC, Wei RDM, James VS, et al. The Stonehouse study: secretor status and carriage of Neisseria species. Epidemiol Infect 1989;102:1-10.

6 Nadel S, Newport MJ, Booy R, et al. Variation in the tumor necrosis factoralpha gene promoter region may be associated with death from meningococcal disease. J Infect Dis 1996;174:878-80.

7 Cartwright K. Meningococcal carriage and disease. In: Cartwright K, eds. Meningococcal disease. Chichester: John Wiley \& Sons Ltd, 1995:115-46.

8 Stanwell-Smith RE, Stuart JM, Hughes AO, et al. Smoking, the environment and meningococcal disease: a case control study. Epidemiol Infect 1994;112:315-28.

9 Young LS, LaForce FM, Head JJ, et al. A simultaneous outbreak of meningococcal and influenza infections. N Engl J Med 1972;287:5-9

10 Krasinski K, Nelson JD, Butler S, et al. Possible association of mycoplasma and viral respiratory infections with bacterial meningitis. Am J Epidemiol 1987; 125:499-508.

11 Haneberg B, Tonjum T, Rodahl K, et al. Factors preceding the onset of meningococcal disease, with special emphasis on passive smoking, symptoms of ill health. NIPH Ann 1983;6:169-73.

12 Stuart JM, Cartwright KA, Dawson JA, et al. Risk factors for meningococcal disease: a case control study in south west England. Community Med 1988; 10:139-46.

13 Ellison RT III, Kohler PF, Curd JG, et al. Prevalence of congenital or acquired complement deficiency in patients with sporadic meningocococcal disease. N Engl J Med 1983;308:913-16.

14 Hibberd ML, Sumiya M, Summerfield JA, et al. Association of variants of the gene for mannose-binding lectin with susceptibility to meningococcal disease. Meningococcal Research Group. Lancet 1999;353:1049-53.

15 Kriz P, Bobak M, Kriz B. Parental smoking, socioeconomic factors, and risk of invasive meningococcal disease in children: a population based case-control study. Arch Dis Child 2000;83:117-21.

16 Jones IR, Urwin G, Feldman RA, et al. Social deprivation and bacterial meningitis in north east Thames region: three year study using small area statistics. BMJ 1997;314:794-5.

17 Stuart JM, Middleton N, Gunnell DJ. Socioeconomic inequality and meningococcal disease. Commun Dis Public Health 2002:5:327-8.

18 Fone DL, Harries JM, Lester N, et al. Meningococcal disease and social deprivation: a small area geographical study in Gwent, UK. Epidemiol Infect 2003; 130:53-8.

19 Dowell SF, Kupronis BA, Zell ER, et al. Mortality from pneumonia in children in the United States, 1939 through 1996. N Engl J Med 2000;342: 1399-407.

20 Ezzati M, Lopez AD, Rodgers A, et al. Selected major risk factors and global and regional burden of disease. Lancet 2002;360:1347-60. 
21 Townsend $\mathrm{P}$, Phillimore $\mathrm{P}$, Beattie $\mathrm{A}$. Health and deprivation: inequality and the North. London: Croom Helm, 1988.

22 Ramsay M, Kaczmarski E, Rush M, et al. Changing patterns of case ascertainment and trends in meningococcal disease in England and Wales. CDR Rev 1997:7:R49-54.

23 Davison KL, Crowcroft NS, Ramsay ME, et al. Enhanced surveillance scheme for suspected meningococcal disease in five regional health authorities in England: 1998. Commun Dis Public Health 2002;5:205-12.

24 Guiver M, Borrow R, Marsh J, et al. Evaluation of the Applied Biosystems automated Taqman polymerase chain reaction system for the detection of meningococcal DNA. FEMS Immunol Med Microbiol 2000;28:173-9.

25 Booy R, Habibi P, Nadel S, et al. Reduction in case fatality rate from meningococcal disease associated with improved healthcare delivery. Arch Dis Child 2001;85:386-90.

26 Thorburn K, Baines P, Thomson A, et al. Mortality in severe meningococcal disease. Arch Dis Child 2001;85:382-5.

27 Baker M, McNicholas A, Garrett N, et al. Household crowding a major risk factor for epidemic meningococcal disease in Auckland children. Pediatr Infect Dis J 2000;19:983-90.
28 Edwards A, Pill R. Patterns of help-seeking behaviour for toddlers from two contrasting socio-economic groups: new evidence on a neglected topic. Fam Pract 1996;13:377-81.

29 Fleming DM, Charlton JR. Morbidity and healthcare utilisation of children in households with one adult: comparative observational study. BMJ 1998;316:1572-6

30 Kai J. What worries parents when their preschool children are acutely ill, and why: a qualitative study. BMJ 1996;313:983-6.

31 Nadel S, Britto J, Booy R, et al. Avoidable deficiencies in the delivery of health care to children with meningococcal disease. J Accid Emerg Med 1998;15:298-303

32 Fleming DM, Smith GE, Charlton JR, et al. Impact of infections on primary care-greater than expected. Commun Dis Public Health 2002:5:7-12.

33 Piantadosi S, Byar DP, Green SB. The ecological fallacy. Am J Epidemio 1988; 127:893-904.

34 Sazawal S, Black RE. Meta-analysis of intervention trials on casemanagement of pneumonia in community settings. Lancet 1992;340:528-33.

35 Gulliford M, Figueroa-Munoz J, Morgan M, et al. What does 'access to health care' mean? J Health Serv Res Policy 2002;7:186-8.

\section{Call for Book Reviewers}

Book reviews are a popular feature of $A D C$, and many readers use them to decide how best to spend scarce library funds. We need to recruit a team of willing reviewers, both generalists and specialists, who are prepared to read and review new books (and CD-ROMs, etc) within a three-month deadline: could you help? You will have the option to decline if you can't manage a review in time.

Unfortunately $A D C$ cannot pay reviewers, but you will be able to keep the book for yourself or your department. Trainees are particularly welcome to apply.

For logistical reasons reviewers should be based in the UK or Republic of Ireland and internet access is essential.

Please contact archdischild@bmigroup.com with brief details of special interests and reviewing experience, if any (include BOOK REVIEWS in the subject field). 